1

2

3

4

5

6

7

8

9

10

11

12 13

14

15

16

17

18

19

20

21

22

23

24

\title{
An experimental study of symmetry lowering of analcime
}

\author{
Neo Sugano and Atsushi Kyono
}

Division of Earth Evolution Sciences, Graduate School of Life and Environmental Sciences, University of Tsukuba, 1-1-1 Tennodai, Tsukuba, Ibaraki, 305-8572, Japan

Corresponding author: A. Kyono

Email: kyono@geol.tsukuba.ac.jp

Phone: +81-29-853-7176

Fax: +81-29-853-7887

orcid.org/0000-0001-5419-390X 
Abstract

Single crystals of analcime were hydrothermally synthesized from a gel of analcime composition at $200{ }^{\circ} \mathrm{C}$ for $24 \mathrm{~h}$. They were grown up to $100 \mu \mathrm{m}$ in size with typical deltoidal icositetrahedron habit. The chemical composition determined by EPMA and TG analyses was $\mathrm{Na}_{0.84}\left(\mathrm{Al}_{0.89} \mathrm{Si}_{2.12}\right) \mathrm{O}_{6} \cdot 1.04 \mathrm{H}_{2} \mathrm{O}$. The single-crystal X-ray diffraction method was used to determine the symmetry and crystal structure of analcime. The analcime grown from a gel crystallized in cubic space group Ia3d with lattice parameter $a=13.713$ (3) $\AA$. In the cubic analcime, Si and $\mathrm{Al}$ cations were totally disordered over the framework $T$ sites with site occupancy of Si:Al = 0.6871:0.3129(14). The single crystals of analcime with cubic symmetry were hydrothermally reheated at $200{ }^{\circ} \mathrm{C}$ in ultrapure water. After the hydrothermal treatment

Keywords: Analcime, Single-crystal X-ray diffraction, Symmetry lowering, Si/Al ordering 
Analcime, ideal chemical formula $\mathrm{NaAlSi}_{2} \mathrm{O}_{6} \cdot \mathrm{H}_{2} \mathrm{O}$, is formed in a variety of geological environments that span a wide range of temperature and pressure from ambient to magmatic conditions (Neuhoff et al. 2004). Analcime is known to occur as a primary mineral in igneous rocks, a hydrothermal mineral occurring in veins and miarolitic cavities, and a secondary mineral in sedimentary rocks or altered pegmatites (Gaines et al. 1997), but the occurrences still remain a question as to whether it is primary or secondary (formed from leucite) (Wilkinson 1977; Karlsson and Clayton 1991; Pearce 1993; Demeny et al. 1997; Prelević et al. 2004; Seryotkin and Bakakin 2008; Henderson et al. 2014). The crystal structure of analcime is composed of a three dimensional framework of $\mathrm{SiO}_{4}$ and $\mathrm{AlO}_{4}$ tetrahedra with the ANA-type topology (Baerlocher et al., 2007). The ANA framework includes four-, six-, and eightmembered rings of the tetrahedra in the structure. The ANA-type is a common framework groups, and the following six natural zeolites belong to the ANA structure: analcime $\mathrm{Na}\left[\mathrm{AlSi}_{2} \mathrm{O}_{6}\right] \cdot \mathrm{H}_{2} \mathrm{O}$, pollucite $(\mathrm{Cs}, \mathrm{Na})\left[\mathrm{AlSi}_{2} \mathrm{O}_{6}\right] \cdot n \mathrm{H}_{2} \mathrm{O}$, wairakite $\mathrm{Ca}\left[\mathrm{Al}_{2} \mathrm{Si}_{4} \mathrm{O}_{12}\right] \cdot 2 \mathrm{H}_{2} \mathrm{O}$, leucite $\mathrm{K}\left[\mathrm{AlSi}_{2} \mathrm{O}_{6}\right]$, ammonioleucite $\left(\mathrm{NH}_{4}\right)\left[\mathrm{AlSi}_{2} \mathrm{O}_{6}\right]$, and hsianghualite $\mathrm{Li}_{2} \mathrm{Ca}_{3}\left[\mathrm{Be}_{3} \mathrm{Si}_{3} \mathrm{O}_{12}\right] \mathrm{F}_{2}(\mathrm{Coombs}$ et al. 1997; Baerlocher et al., 2007). The maximum symmetry of the ANA framework is cubic with space group Ia3d, but naturally occurring analcimes possess at least four different symmetries: cubic space group Ia3d, tetragonal space group $I 4_{1} /$ acd, orthorhombic space group Ibca, and monoclinic space group I2/a (Ferraris et al. 1972; Mazzi and Galli 1978; Hazen and Finger 1979; Pechar 1988; Anthony et al. 1995). In addition to these symmetries, rhombohedral is also theoretically possible (Takéuchi et al. 1979). The previous study led to a conclusion that the symmetry lowering results from strict discrimination between $\mathrm{Si}$ and $\mathrm{Al}$ cations in the tetrahedral (T) sites of the ANA framework (Mazzi and Galli 1978). The ordering of Si and Al in the framework has also been studied using solid-state NMR technique (Murdoch et al. 1988; Teertstra et al. 1994; Phillips and Kirkpatrick 1994; Kohn et al. 1995; Cheng et al. 2000; Kim et al. 2010). Consequently, the ordering of Si and Al can be responsible for the symmetry lowering of analcime from cubic Ia3d to orthorhombic Ibca. With compression, furthermore, the symmetry of analcime changes to triclinic space group $P \overline{1}$, which is driven by tetrahedral tilting (Gatta et al. 2006).

Although natural analcimes exhibit a wide range of symmetries, little studies have been performed to investigate how the $\mathrm{Si}$ and $\mathrm{Al}$ move over the framework $\mathrm{T}$ sites with temperature 
and heating time. Here, we report an experimental study of symmetry lowering of analcime by using single-crystal X-ray diffraction method. This approach toward the symmetry change in analcime would be helpful for investigating the classical mineralogical and petrological question as to whether the analcime is primary or secondary.

\section{Experimental methods}

\section{Hydrothermal experiment}

Single crystals of analcime were hydrothermally synthesized from a gel of analcime composition. First, aluminium sulfate $\mathrm{Al}_{2}\left(\mathrm{SO}_{4}\right)_{3}$ (Wako special grade, Wako Pure Chemical Industries, Ltd., Japan) and sodium metasilicate nonahydrate $\mathrm{Na}_{2} \mathrm{SiO}_{3} \cdot 9 \mathrm{H}_{2} \mathrm{O}$ (purity $>98.0 \%$, Wako Pure Chemical Industries, Ltd., Japan) were used as starting materials. They were stoichiometrically mixed and transferred into a Teflon container with ultrapure water (Wako Pure Chemical Industries, Ltd., Japan). It was placed in an electric oven (DRM320DA, Advantec Toyo Kaisha, Ltd., Japan) and subsequently heated at $200{ }^{\circ} \mathrm{C}$ with autogenic pressure. After 24h, it was quenched into cold water. The products were then filtered and thoroughly rinsed with distilled water. The sample obtained in this way was hydrothermally reheated at 200 ${ }^{\circ} \mathrm{C}$ in the ultrapure water for different duration, after which it was quenched into cold water. The recovered sample was filtered and thoroughly rinsed with distilled water. The morphology of the synthesized products was observed by a field emission scanning electron microscopy (JSM6330F, JEOL Ltd., Japan) with an acceleration voltage of $5 \mathrm{kV}$. Pt-Pd was deposited for conductive treatment by an ion-sputtering coater (E-1045, Hitachi High-Technologies Corporation, Japan) with current of $15 \mathrm{~mA}$ for $120 \mathrm{~s}$.

\section{EPMA and TG-DTA analyses}

Qualitative and quantitative analyses were conducted by a hyperprobe field emission electron probe microanalyzer (EPMA) equipped with wavelength-dispersive X-ray spectrometers (JXA-8530F, JEOL Ltd., Japan). Regarding EPMA analysis of hydrous alkali aluminosilicates, a long-standing problem is sample damage caused by the electron-beam, which is ascribed to the migration of $\mathrm{Na}$ and other alkalis. The migration is known to be permanent and irreversible after irradiation ceases (Autefage and Couderc 1980). The alkali 
losses can be minimized with the use of carefully selected operating conditions. In the present study, to prevent the loss of $\mathrm{NaK} \alpha$ X-ray intensity during electron-beam irradiation, measurements were performed under the experimental conditions based on the recommendation of Morgan and London $(1996,2005)$ and on the recent study of natural zeolites (Campbell et al. 2016). In the study, the X-ray spectra were thus measured using a beam diameter of $20 \mu \mathrm{m}$, an accelerating voltage of $15 \mathrm{kV}$, and a beam current of $2 \mathrm{nA}$ with an acquisition time of $30 \mathrm{~s}$ on both the peak and background. Quartz ( $\mathrm{SiK} \alpha)$, corundum ( $\mathrm{AlK \alpha})$, and albite $(\mathrm{NaK \alpha})$ were used as standards. No other elements were detected in the qualitative analyses. Raw data obtained were corrected using a conventional ZAF program. The chemical formulae of analcime were finally determined based on six oxygen atoms per formula unit (apfu).

In the study, thermogravimetry (TG) measurements were performed to obtain a reliable water content of analcime. Thermogravimetric (TG) and differential thermal analyses (DTA) were carried out with a TG/DTA thermal analyzer (EXTRA7000 TG/DTA7300, Seiko Instruments Inc., Japan). The samples of approximately $10 \mathrm{mg}$ were mounted on an aluminum pan and heated under Ar gas flow of $200 \mathrm{ml} / \mathrm{min}$. The temperature was increased from $55^{\circ} \mathrm{C}$ to $550{ }^{\circ} \mathrm{C}$ at a heating rate of $10{ }^{\circ} \mathrm{C} / \mathrm{min}$. $\mathrm{Al}_{2} \mathrm{O}_{3}$ powder was used for the reference. As the previous studies had also indicated (Kim and Kirkpatrick 1998; Cruciani and Gualtieri 1999; Chipera and Bish 2010), the present TG-DTA measurement showed that analcimes kept $100 \% \mathrm{H}_{2} \mathrm{O}$ content until $100{ }^{\circ} \mathrm{C}$ and were completely dehydrated by $450{ }^{\circ} \mathrm{C}$. The numbers of $\mathrm{H}_{2} \mathrm{O}$ molecule per formula unit were therefore estimated by weight loss between $100{ }^{\circ} \mathrm{C}$ and $450{ }^{\circ} \mathrm{C}$. The chemical composition of analcimes determined by EPMA and TG analyses are listed in Table 1.

\section{Single-crystal X-ray diffraction study}

For the single-crystal X-ray diffraction measurement, suitable single crystals were selected under a microscope. They were fixed at the top of $0.1 \mathrm{~mm}$ diameter glass fibers and mounted on a goniometer head. X-ray diffraction measurements were performed by using a single-crystal diffractometer (APEXII ULTRA, Bruker AXS Inc., Germany) equipped with a CCD detector, multilayer optics, and graphite monochromated MoKa radiation $(\lambda=0.71073$ $\AA \AA$ ) generated by a rotating anode. The sample-to-detector distance was set to $60 \mathrm{~mm}$. A preliminary 36 frames of two dimensional diffraction images were collected and processed to 
obtain the cell parameters and orientation matrix. A total of 720 frames covering a hemisphere of reciprocal space were collected with a step size of $0.5^{\circ}$ in $\omega$ at three different $\varphi$ setting $(0,90$, $180^{\circ}$ ) and detector position of $-28^{\circ}$ in $2 \theta$. The exposure time was $10 \mathrm{~s}$ per frame. Intensity data were integrated and corrected for Lorentz-polarization effects using the APEX2 software (Bruker 2006). Empirical absorption correction was also applied using the SADABS software (Sheldrick 1999). The space group symmetries were determined from the systematic absences. The structures were solved by a combination of the direct method and the difference Fourier methods provided by the program package SHELXTL (Bruker 1998). Unique reflections with $F_{0}>4 \sigma\left(F_{0}\right)$ were used in the structure refinements. Site occupancy parameters of $\mathrm{Si}$ and $\mathrm{Al}$ on the framework $T$ sites were refined under a constraint that the total populations on each $T$ site were unity, whereas those of $\mathrm{Na}$ cations were refined without any constraint. The crystal structures were finally refined by full matrix least-square methods on $F^{2}$ using SHELXL97 software (Sheldrick 1997). Since hydrogen atoms were not included in the calculations, water molecules were refined as oxygen atoms in the refinements. All atoms were refined on the basis of anisotropic displacement model. The crystallographic data, data collection, and structure refinement details are shown in Table 2 . The refined structural parameters are given in Table 3. Selected bond distances are summarized in Table 4.

\section{Chemical composition}

Euhedral single crystals with the size up to approximately $100 \mu \mathrm{m}$ were obtained from the gel. The single crystals grown in the study exhibited typical deltoidal icositetrahedron habit (Fig. 1a). The chemical compositions of as-grown analcime and its hydrothermally reheated samples are given in Table 1. The results of EPMA measurement show that the single crystals are chemically homogeneous and close to the ideal chemical composition of analcime. The totals of tetrahedral cations are approximately 3.00 atoms per formula unit (apfu), but the contents of Si ranges between 2.10 and 2.15 apfu. The contents of $\mathrm{Na}$ are, on the other hand, about $0.85 \mathrm{apfu}$, which is considerably less than the ideal value. The deficiencies of $\mathrm{Na}$ in extraframework sites result from the excess positive charge on the framework caused by the excess Si. If the contents of $\mathrm{H}_{2} \mathrm{O}$ molecule are estimated by the deficit of the total oxide weight from 
$100 \mathrm{wt} \%$, they are ranged from 10.2 to $11.2 \mathrm{wt} \%$. They correspond to 1.26 to 1.39 molecules per formula unit. The estimations are much higher than the ideal value of 1.00 molecule per formula unit. As Deer et al. (2004) have already pointed out, estimating water content by difference from 100 wt\% by EPMA measurement never yield useful results. Thus, we determined the water contents in analcime by the thermogravimetry (TG) curves. In the present study, the weight losses between 100 and $450{ }^{\circ} \mathrm{C}$ were $8.4 \mathrm{wt} \%$, which correspond to 1.03 to 1.04 molecules per formula unit. The $\mathrm{H}_{2} \mathrm{O}$ contents obtained from the TG analysis are thus consistent approximately with the ideal value.

Putnis et al. (2007) reported that in hydrothermal reaction between analcime and leucite replacement of leucite by analcime proceeds by both dissolution of leucite and reprecipitation of analcime. They exhibited the SEM image showing crystal surfaces which are covered with the rough and porous surface layers of analcime. In the present study, however, no surface features indicating the dissolution and reprecipitation process were produced by the hydrothermal treatment (Fig. 1b, d). The most noteworthy feature in the present study is that the concentrations of $\mathrm{Na}, \mathrm{Al}$, and $\mathrm{Si}$ almost remained unchanged with increasing the hydrothermal heating time up to at least $48 \mathrm{~h}$.

\section{As-grown analcime with cubic symmetry}

No forbidden reflections for the cubic Ia3d symmetry were observed in the analcime grown from gel. The as-grown analcime therefore crystallized in cubic space group Ia3d with lattice parameter $a=13.713$ (3) $\AA$ (Table 2). The lattice parameter was slightly larger than that of naturally occurring cubic analcime, $a=13.7065(8) \AA$, with a chemical formula of $\left(\mathrm{Na}_{0.887} \mathrm{~K}_{0.001} \mathrm{Ca}_{0.001}\right)\left(\mathrm{Al}_{0.905} \mathrm{Si}_{2.102}\right) \mathrm{O}_{6} \cdot 0.994 \mathrm{H}_{2} \mathrm{O}$ (Gatta et al. 2006). In the cubic analcime with the space group Ia3d, the framework $T$ site is located on $48 \mathrm{~g}$ Wyckoff positions, and hence 48 tetrahedra are symmetrically equivalent. The framework $T$ site is randomly occupied with site occupancy of $\mathrm{Si}: \mathrm{Al}=0.6871: 0.3129(14)$ (Table 3). The $T$-O bond lengths ranging from $1.6430(11)$ to $1.6465(11) \AA$ (Table 4) agree well with the values reported in the previous study (Gatta et al. 2006). The T-O bond lengths are an indicator of Si/Al disordering. Wairakite belongs to a group of minerals with the ANA-type framework topology and has a fully ordered Si/Al distribution (Takéuchi et al. 1979; Seryotkin et al. 2003). The completely ordered Si-O and Al-O bond lengths in wairakite are in the ranges of 1.604 to $1.617 \AA$ and of 1.730 to 1.731 $\AA$, respectively (Seryotkin et al. 2003). We established a regression line between the completely 
ordered Si-O and Al-O bond lengths as follows: T-O bond length $(\AA)=0.1215 \times S O P(\mathrm{Al})+$ $1.609\left(R^{2}=0.9952\right)$, where $\operatorname{SOP}(\mathrm{Al})$ is the site occupancy parameter of $\mathrm{Al}$. Assuming that the $T$-O bond lengths reflect only $\mathrm{Al}$ content, the average $T$-O bond length of $1.645 \AA$ obtained in our study corresponds to the Al site occupancy parameter of 0.2963 . This estimation is very close to the refined site occupancy parameter of $\mathrm{Al}[=0.3129(14)$; Table 3]. Analcime, ideal chemical formula $\mathrm{NaAlSi}_{2} \mathrm{O}_{6} \cdot \mathrm{H}_{2} \mathrm{O}$, contains 16 formula units in the unit-cell. In the cubic space group Ia3d, Na is located on the Wyckoff positions $24 c$ with multiplicity 24. The maximum site occupancy of Na is therefore 16/24. In the present study, the resulting site occupancy parameter of $\mathrm{Na}$ is $0.6040(14)$ (Table 3), implying that the number of Na corresponds to $0.906 \mathrm{apfu}$. As a result, the chemical formula obtained from the site occupancy parameters is $\mathrm{Na}_{0.906}\left(\mathrm{Al}_{0.939} \mathrm{Si}_{2.061}\right) \mathrm{O}_{6} \cdot \mathrm{H}_{2} \mathrm{O}$, which is similar to that of the naturally occurring cubic analcime (Gatta et al. 2006). In the analcime, Na cation is octahedrally coordinated by four framework oxygen atoms and two water molecules. The Na-O bond lengths were longer than the Na- $W$ bond lengths (Table 4). The longer Na-O bond lengths arise from the deficiency of $\mathrm{Na}$ in the extra-framework sites (Mazzi and Galli 1978). Compared with the Na-O and Na- $W$ bond lengths refined by Gatta et al. (2006), they are entirely consistent with the values obtained in the present study. The chemical formula obtained from the EPMA and TG analyses is, on the other hand, $\mathrm{Na}_{0.84}\left(\mathrm{Al}_{0.89} \mathrm{Si}_{2.12}\right) \mathrm{O}_{6} \cdot 1.04 \mathrm{H}_{2} \mathrm{O}$ (Table 1). The chemical characteristic of excess Si and deficiencies of $\mathrm{Na}$ and $\mathrm{Al}$ is in good agreement with the result of crystal structural analysis. Taking the structural and chemical similarities into consideration, there is no significant difference between naturally occurring analcime and analcime hydrothermally grown in the present study.

According to the previous paper (Coombs et al. 1997), the basic structure of zeolite is an aluminosilicate framework composed of $\mathrm{SiO}_{4}$ and $\mathrm{AlO}_{4}$ tetrahedra. The framework is negatively charged and attracts the positive cations in the open cages. The negative charge of the framework results from the substitution of $\mathrm{Si}^{4+}$ by $\mathrm{Al}^{3+}$, which is compensated by alkaline cations. With increasing the $\mathrm{Si} / \mathrm{Al}$ ratio in the framework, the $\mathrm{Na}$ and $\mathrm{Al}$ contents decrease, but the $\mathrm{H}_{2} \mathrm{O}$ content increases. In the cubic analcime, a Na atom is octahedrally coordinated with four framework oxygens with Na-O distance of 2.5007(12) $\AA$ and two water molecules with Na-W distance of 2.4241(5) A. Water molecules are, on the other hand, located at the center of the wide cages of the framework structure. The $\mathrm{H}_{2} \mathrm{O}$ molecule is connected not only to the $\mathrm{Na}$ but also to the framework oxygens with weak hydrogen bonding. There are six hydrogen bonds 
between the water molecule and framework oxygen with $\mathrm{W} \cdots \mathrm{O}$ distance of 3.4055(14) $\AA$ and the other six hydrogen bonds with $\mathrm{W} \cdots \mathrm{O}$ distance of 3.5584(14) $\AA$. The $\mathrm{H}_{2} \mathrm{O}$ molecules are surrounded by the 12 weak hydrogen bonds in the wide cages. Therefore, even if the $\mathrm{Na}$ polyhedron is lost from the cage, the water molecule can remain around the center of cage with the hydrogen bond. The Na deficiency is fairly common in analcime (e.g., Pechar 1988, Line et al. 1995, Cruciani and Gualtieri 1999, Neuhoff et al. 2004, Gatta et al. 2006, Campbell et al. 2016), but the number of $\mathrm{H}_{2} \mathrm{O}$ molecules never decreases with decreasing the Na content.

\section{Symmetry lowering by Si/Al ordering with hydrothermal treatment}

After the hydrothermal treatment of analcime at $200{ }^{\circ} \mathrm{C}$ for $24 \mathrm{~h}$, weak reflections of type $00 l$ with $l=2 n$ became observed, which correspond to the reflection conditions of orthorhombic Ibca. When a phase transformation is examined from reflection conditions, the greatest care should be given to the multiple diffraction because the observation of the multiple diffraction spots often lead to an incorrect space group. We carefully checked the symmetrically equivalent reflections of $00 l$ reflections with $l=2 n$ and analyzed their intensity profiles over the rocking angle. In the present study, the equivalent reflections 0010 and $00 \overline{10}$ were examined and their intensity profiles are shown in Figure 2. Comparing between both the reflections, the shapes of the two intensity profiles are almost identical. Furthermore, the intensity profiles over the rocking angle and their least-squares curves fitted to a Gaussian function are shown in Figure 2c and 2d. The Gauss areas, corresponding to the integrated intensities, of 0010 and $00 \overline{10}$ reflections are 321.3 and 310.7, respectively; the difference between both is only 3.3\%. Since the intensity profile of both the reflections are thus very close, it is unlikely that they were caused by the multiple diffraction. Therefore, we concluded from the appearance of the $00 l$ reflections with $l=2 n$ that symmetry of the analcime changes to orthorhombic Ibca with the hydrothermal treatment for $24 \mathrm{~h}$.

The lattice parameters refined with the orthorhombic cell were $a=13.727(2) \AA, b=$ 13.707(2) $\AA$, and $c=13.707(2) \AA$ (Table 2). The unit-cell exhibits a slight distortion with $(a+$ b)/2 >c, yielding a flattened cell along $c$. With the symmetry lowering of cubic analcime, crystallographically equivalent positions are split into inequivalent positions (Fig. 3). In the cubic Ia3d, the framework $T$ site and extra-framework Na site are located on $48 \mathrm{~g}$ and $24 \mathrm{c}$ Wyckoff positions, respectively. The $W$ site is on $16 b$ Wyckoff positions. As it can be seen in Figure $3 b$, with symmetry lowering to the tetragonal $I 4_{1} / a c d$, the framework $T$ site on $48 \mathrm{~g}$ is 
split into the $T 1$ site on $32 g$ and $T 2$ site on $16 f$. The Na site on $24 c$ is split into Na1 site on $16 e$ and Na2 site on $8 b$. The $W$ site on $16 b$ is transformed to $16 f$. With further symmetry lowering to the orthorhombic Ibca (Fig. 3c), the $T 1$ site on $32 \mathrm{~g}$ is split into $T 11$ and $T 12$ sites on $16 f$. The Na1 site on $16 e$ is split into Na11 on $8 c$ and Na12 on $8 d$. The Na2 site on $8 b$ is transformed to $8 e$. With the hydrothermal treatment for $24 \mathrm{~h}, \mathrm{Si}$ and $\mathrm{Al}$ cations in the orthorhombic phase showed a slightly ordered distribution over the three framework $T$ sites with site occupancy of Si:Al = 0.618:0.382(2) on T11, 0.681:0.319(2) on T12, and 0.687:0.313(2) on T2 (Table 3). The most important feature in the present study is that $\mathrm{Al}$ exhibits a site preference for $\mathrm{T} 11$ site in the orthorhombic phase. Mazzi and Galli (1978) reported that the degree of unit-cell distortion in analcime depends on the $\mathrm{Al}$ fraction in the $\mathrm{T}$ sites: the flattened cell is caused by a higher $\mathrm{Al}$ fraction in $T 1$ site, whereas the elongated cell is by a higher $\mathrm{Al}$ fraction in $T 2$ site. This trend is entirely consistent with the case of the present orthorhombic analcime with the Al preference for $T 11$ site derived from the tetragonal $T 1$ site. The T11-O, T12-O and T2-O bond lengths are in the ranges of $1.6414(15)$ to $1.6477(16) \AA, 1.6408(15)$ to $1.6463(16) \AA$, and $1.6411(15)$ to 1.6457(16) A, respectively (Table 4). Despite the Al ordering in the $T$ sites, thus, we could detect no significant difference in the $T$-O bond length among the $T 11, T 12$, and $T 2$ sites. Site occupancies of Na11, Na12, and Na2 were 0.591(2), 0.598(2), and 0.596(2), respectively (Table 3). Na exhibits no significant site preference among the three Na sites, which is a similar feature to the naturally occurring analcime (Mazzi and Galli 1978). In the octahedral coordination of $\mathrm{Na}$ sites, the Na-O and Na- $W$ bond lengths almost remain unchanged with the hydrothermal treatment for $24 \mathrm{~h}$. As-grown analcime, hydrothermally formed from gel at $200{ }^{\circ} \mathrm{C}$ for $24 \mathrm{~h}$, might be frozen as the metastable cubic phase. With the additional heating time for $24 \mathrm{~h}$, the analcime would reach to the equilibrium state to change into the stable orthorhombic phage.

After the hydrothermal treatment for $48 \mathrm{~h}$, reflections of type $00 l$ with $l=2 n$ appeared as well, which is consistent with the orthorhombic space group Ibca. The observed forbidden reflections were examined in the same way as the case of the hydrothermal treatment for 24h; consequently, they were concluded to be not due to the multiple diffraction. Lattice parameters with orthorhombic cell were $a=13.705(2) \AA, b=13.717(2) \AA$, and $c=13.706(2) \AA$, which retains the flattened cell shape with $(a+b) / 2>c$. The refined site occupancy parameters for $\mathrm{Si}$ and $\mathrm{Al}$ are $\mathrm{Si}: \mathrm{Al}=0.603: 0.397(6)$ on $T 11,0.694: 0.306(6)$ on $T 12$, and 0.687:0.313(6) on $T 2$ (Table 3). With the hydrothermal treatment for $48 \mathrm{~h}, \mathrm{Al}$ is further concentrated into $T 11$ site. It is noteworthy that the $\mathrm{Si} / \mathrm{Al}$ ordering was slightly but significantly accelerated with the 
hydrothermal treatment time. The T11-O, T12-O, and T2-O bond lengths are in the ranges of $1.6416(14)$ to $1.6460(15) \AA, 1.6415(14)$ to $1.6458(15) \AA$, and $1.6424(15)$ to $1.6467(15)$, respectively (Table 4). Thus, there is no significant difference in the $T$-O bond length among the $T 11, T 12$, and $T 2$ sites, as well as the case of the hydrothermal treatment for $24 \mathrm{~h}$. The site occupancies in Na11, Na12, and Na2 sites are 0.594(2), 0.602(2), and 0.600(2), respectively (Table 3), which indicates that there is no significant site preference of Na cation over the three extra-framework sites, as well as the analcime hydrothermally heated for $24 \mathrm{~h}$. During the hydrothermal reaction, chemical compositions were consequently almost unchanged. Since the site occupancies of Na over the extra-framework sites remained unaffected with increasing the heating time, the result shows that the heating time influences the degree of ordering of Si and Al over the framework $T$ sites.

Two ordering models can be considered for the $\mathrm{Si} / \mathrm{Al}$ ordering in the framework $T$ sites. The first case is that the ordering gives rise to a site splitting of a $T$ site into two crystallographycally inequivalent sites. In the present study, we experimentally confirmed the symmetry lowering of analcime induced by $\mathrm{Si} / \mathrm{Al}$ ordering among the framework $T$ sites. The second case is that the ordering proceeds continuously within the $T$ sites, keeping the symmetry. Tetragonal analcimes with highly ordered $\mathrm{Si} / \mathrm{Al}$ distribution in the $T$ sites have been already reported (Mazzi and Galli 1978; Cruciani and Gualtieri 1999). In the tetragonal analcime, one edge of tetrahedron of $T 1$ site shares with that of octahedron of Na site. Therefore, Mazzi and Galli (1978) exhibited that there is a direct relationship between Na occupancy and Al fraction in the nearest $T 1$ site. That is to say, the highly ordered $\mathrm{Si} / \mathrm{Al}$ distribution among the $T$ sites must be caused by the high occupancy of $\mathrm{Na}$ in the extra-framework sites. In our experiment, as-grown cubic analcime was hydrothermally heated with ultrapure water in the Teflon container. During the hydrothermal treatment, no additional sodium source was supplied in the solution. This would be the reason why the $\mathrm{Si} / \mathrm{Al}$ ordering was not drastically accelerated with the hydrothermal reaction. In other word, analcime with highly ordered $\mathrm{Si} / \mathrm{Al}$ distribution among the $T$ sites might be formed, when it is reheated under Na-rich solution.

\section{CONCLUSIONS}

In the study, a symmetry lowering of analcime from cubic Ia3d to orthorhombic Ibca was experimentally confirmed. With the hydrothermal treatment at $200{ }^{\circ} \mathrm{C}$ for $24 \mathrm{~h}, \mathrm{Al}$ in the 
framework $T$ site is preferentially concentrated into $T 11$ site, which yields three inequivalent $T$ sites. The site splitting leads to the symmetry lowering from cubic Ia3d to orthorhombic Ibca. During the hydrothermal treatment, chemical composition was almost unchanged. Since Si/Al ordering was slightly but significantly accelerated with heating time, whereas the site occupancies of Na over the extra-framework sites remained unaffected with heating time. Thus, the result clearly shows that the heating time influences the degree of ordering of Si and $\mathrm{Al}$ over the framework $T$ sites rather than that of Na among the extra-framework sites.

\section{ACKNOWLEDGMENTS}

We appreciate the incisive reviews by Akihiko Nakatsuka and an anonymous reviewer, which led to numerous improvements in the manuscript. We also thank Taku Tsuchiya for his editorial handling. The work was partially supported by a Grant-in-Aid for Scientific Research (C) from the Japan Society for the Promotion of Science (project no. 26400511).

Anthony JW, Bideaux RA, Bladh KW, Nichols MC (1995) Handbook of mineralogy. vol. II, Silica, silicates, part 1, pp. 446, Mineral Data Publishing, Tucson, Arizona

Autefage F, Couderc J-J (1980) Étude du mécanisme de la migration du sodium et du potassium au cours de leur analyse à la microsonde électronique. Bull de Minéral 103:623-629

Baerlocher CH, McCusker LB, Olson DH (2007) Atlas of zeolite framework types. pp.398, Elsevier, Amsterdam

Bruker (1998) SHELXTL: structure determination programs Ver. 5.16. Bruker AXS Inc., Madison, Wisconsin, USA

Bruker (2006) Apex2 Version 2; Data collection and processing software. Bruker AXS Inc., Madison, Wisconsin, USA

Campbell LS, Charnock J, Dyer A, Hillier S, Chenery S, Stoppa F. Henderson CMB, Walcott R, Rumsey M (2016) Determination of zeolite-group mineral compositions by electron probe microanalysis. Mineral Mag 80:781-807 
Cheng X, Zhao PD, Stebbins JF (2000) Solid state NMR study of oxygen site exchange and AlO-Al site concentration in analcime. Am Mineral 85:1030-1037

Chipera, SJ, Bish, DL (2010) Rehydration kinetics of a natural analcime. Eur J Mineral 22:787-795

Coombs DS, Alberti A, Armbruster T, Artioli G, Colella C, Galli E, Grice JD, Liebau F, Mandarino JA, Minato H, Nickel EH, Passaglia E, Peacor DR, Quartieri S, Rinaldi R, Ross M, Sheppard RA, Tillmanns E, Vezzalini G (1997) Recommended nomenclature for zeolite minerals: Report of the Subcommittee on Zeolites of International Mineralogical Association, Commission on New Minerals and Minerals Names. Can Mineral, 35:1571-1606

Cruciani G, Gualtieri A (1999) Dehydration dynamics of analcime by in situ synchrotron powder diffraction. Am Mineral 84:112-119

Deer WA, Howie RA, Wise WS, Zussman J (2004) Rock-Forming Minerals, 4B Framework silicates - silica minerals, feldspathoids and zeolites. 982 p. The Geological Society, London

Demeny A, Harangi S, Forizs I, Nagy G (1997) Primary and secondary features from analcimes formed in carbonate-zeolite ocelli of alkaline basalts (Mecsek Mts., Hungary): textures, chemical and oxygen isotope compositions. Geochem J 31:37-47

Ferraris G, Jones DW, Yerkess J (1972) A neutron-diffraction study of the crystal structure of analcime, $\mathrm{NaAlSi}_{2} \mathrm{O}_{6} \cdot \mathrm{H}_{2} \mathrm{O}$. Z Kristallogr 135:240-252

Gaines RV, Skinner HCW, Foord EE, Mason B, Rosenzweig A (1997) Dana’s new mineralogy: the system of mineralogy of James Dwight Dana and Edward Salisbury Dana. 8th ed., pp 854, Wiley, New York

Gatta GD, Nestola F, Ballaran TB (2006) Elastic behavior, phase transition, and pressure induced structural evolution of analcime. Am Mineral 91:568-578

Hazen RM, Finger LW (1979) Polyhedral tilting: A common type of pure displacive phase transition and its relationship to analcime at high pressure. Phase Transitions, 1:1-22

Henderson CMB, Hamilton DL, Waters JP (2014) Phase equilibria in $\mathrm{NaAlSiO}_{4}-\mathrm{KAlSiO}_{4}-$ $\mathrm{SiO}_{2}-\mathrm{H}_{2} \mathrm{O}$ at $100 \mathrm{MPa}$ pressure: equilibrium leucite composition and the enigma of primary analcime in blairmorites revisited. Mineral Mag 78:171-202

Karlsson HR, Clayton RN (1991) Analcime phenocrysts in igneous rocks: primary or secondary? Am Mineral 76:189-199 
Kim Y, Kirkpatrick RJ (1998) High-temperature multi-nuclear NMR investigation of analcime. Am Mineral 83:339-347

Kim Y, Lee SK, Kirkpatrick RJ (2010) Effects of intermediate range structure on the Si-29 NMR chemical shifts of framework silicates: Results for analcime. Am Mineral 95:1694-1700

Kohn SC, Henderson CMB, Dupree, R (1995) Si-Al order in leucite revisited: New information from an analcite-derived analogue. Am Mineral 80:705-714

Line CM, Purnis A, Purnis C, Giampaolo C (1995) The dehydration kinetics and microtexture of analcime from two parageneses. Am Mineral, 80:268-279

Mazzi F, Galli E (1978) Is each analcime different? Am Mineral 63:448-460

Morgan GB, London D (1996) Optimizing the electron microprobe analysis of hydrous alkali aluminosilicate glasses. Am Mineral 81:1176-1185

Morgan GB, London D (2005) Effect of current density on the electron microprobe analysis of alkali aluminosilicate glasses. Am Mineral 90:1131-1138

Murdoch JB, Stebbins JF, Carmichael ISE, Pines A (1988) A silicon-29 nuclear magnetic resonance study of silicon-aluminum ordering in leucite and analcite. Phys Chem Miner 15:370-382

Neuhoff PS, Hovis GL, Balassone G, Stebbins JF (2004) Thermodynamic properties of analcime solid solutions. Am J Sci 304:21-66

Pearce TH (1993) Analcime phenocrysts in igneous rocks: primary or secondary? -discussion. Am Mineral 78:225-229

Pechar F (1988) The crystal structure of natural monoclinic analcime $\left(\mathrm{NaAlSi}_{2} \mathrm{O}_{6} \cdot \mathrm{H}_{2} \mathrm{O}\right)$. Z Kristallogr 184:63-69

Phillips BL, Kirkpatrick RJ (1994) Short-range Si-Al order in leucite and analcime: Determination of the configurational entropy from ${ }^{27} \mathrm{Al}$ and variable-temperature ${ }^{29} \mathrm{Si}$ NMR spectroscopy of leucite, its Cs- and Rb-exchanged derivatives, and analcime. Am Mineral 79:1025-1031

Prelević D, Foley SF, Cvetkovic V, Romer RL (2004) The analcime problem and its impact on the geochemistry of ultrapotassic rocks from Serbia. Mineral Mag 68:633-648

Putnis CV, Geisler T, Schmid-Beurmann P, Stephan T, Giampaolo C (2007) An experimental study of the replacement of leucite by analcime. Am Mineral 92:19-26

Seryotkin YV, Joswig W, Bakakin VV, Belitsky IA, Fursenko BA (2003) High-temperature 
Seryotkin YV, Bakakin VV (2008) The thermal behavior of secondary analcime as leucite derivate and its structural interpretation. Russ Geol Geophys 49:153-158

Sheldrick GM (1997) SHELXL97: Program for the refinement of crystal structures. University of Göttingen, Germany

Sheldrick GM (1999) SADABS: Empirical absorption and correction software. University of Göttingen, Germany

Takéuchi Y, Mazzi F, Haga N, Galli E (1979) The crystal structure of wairakite. Am Mineral 64:993-1001

Teertstra DK, Sherriff BL, Xu Z, Cerny P (1994) MAS and DOR NMR study of Al-Si order in the analcime-pollucite series. Can Mineral 32:69-80

Wilkinson JFG (1977) Analcime phencrysts in a vitrophyric analcimite-primary or secondary? Contrib Mineral Petrol 64:1-9 


\section{Captions for Figures and Tables}

453

454

455

456

457

458

459

460

461

462

463

464

465

466

467

468

469

470

471

472

473

474

Figure 1 Field emission scanning electron microscope photographs of the hydrothermally synthesized analcime single-crystals. (a) As-grown sample with the deltoidal icositetrahedron habit and (b) magnified image of the area indicated by the square in (a). (c) Sample after additional hydrothermal treatment at $200^{\circ} \mathrm{C}$ for $24 \mathrm{~h}$ and (d) magnified image of the area indicated by the square in (c).

Figure 2 Intensity profiles recorded by CCD detector. (a) 0010 and (b) $00 \overline{10}$ reflections corresponding to reflection conditions of type $00 l$ with $l=2 n$, which is consistent with the orthorhombic space group Ibca. The rocking curves of the (c) 0010 and (d) $00 \overline{10}$ reflections and their profiles fitted to a Gaussian function.

Figure 3 The six-membered ring channel and extra-framework species of analcime viewed along the [111] direction. The site splitting from (a) the cubic analcime with space group Ia3d to (c) the orthorhombic analcime with space group Ibca through (b) the tetragonal space group $I 4_{1} /$ acd. The terms in the parentheses denote Wyckoff positions.

Table 1 Representative chemical compositions of analcimes

Table 2 Selected X-ray diffraction data and crystallographic information for analcimes.

Table 3 Atomic coordinates, site occupancy parameters, equivalent isotropic, and anisotropic displacement parameters $\left(\AA^{2}\right)$.

Table 4 Selected bond lengths $(\AA)$ in framework $T$ sites and extra-framework sites. 

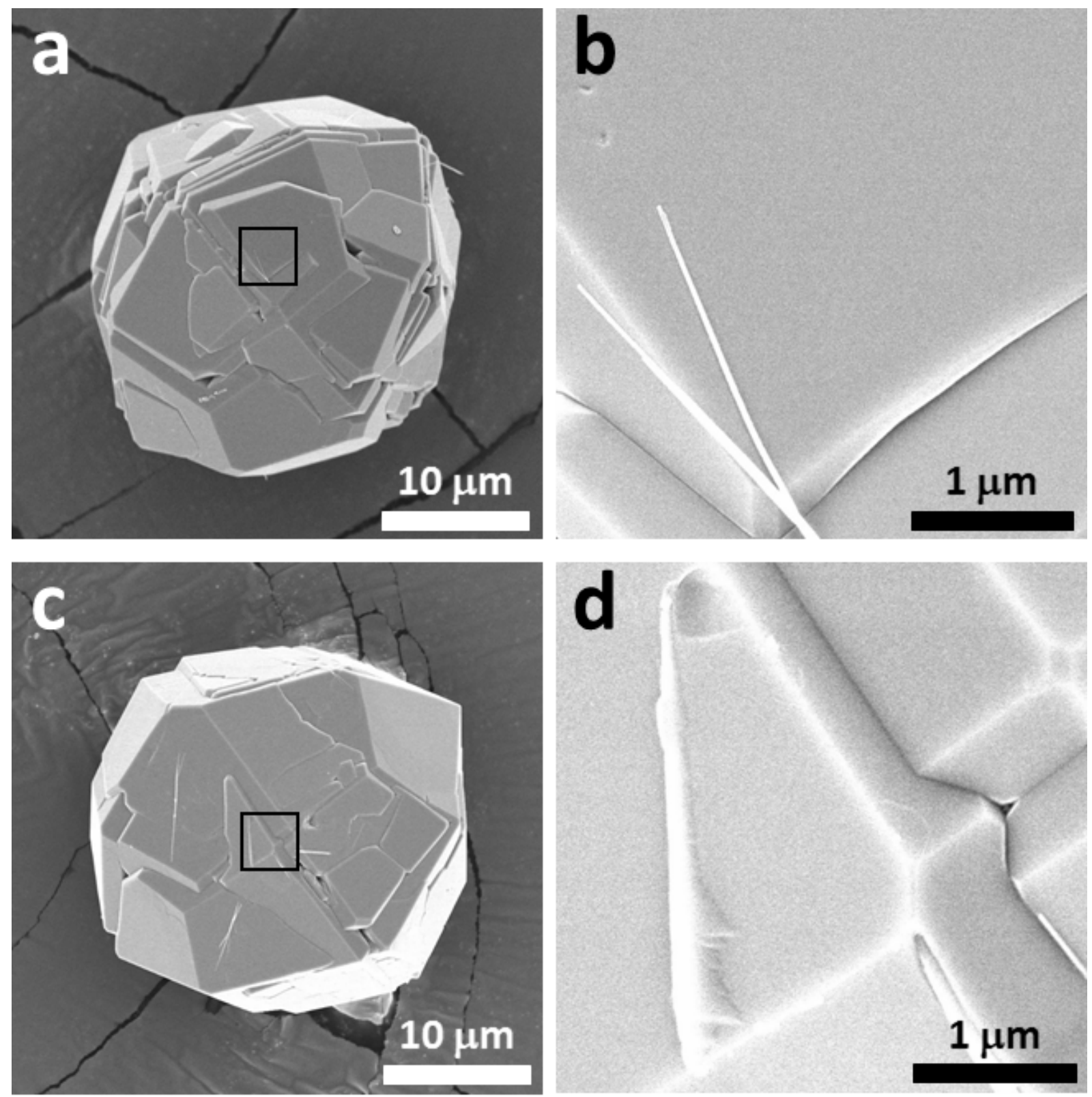

Figure 1 Field emission scanning electron microscope photographs of the hydrothermally synthesized analcime single-crystals. (a) As-grown sample with the deltoidal icositetrahedron habit and (b) magnified image of the area indicated by the square 480 in (a). (c) Sample after additional hydrothermal treatment at $200^{\circ} \mathrm{C}$ for $24 \mathrm{~h}$ and (d) magnified image of the area indicated by the square in (c). 

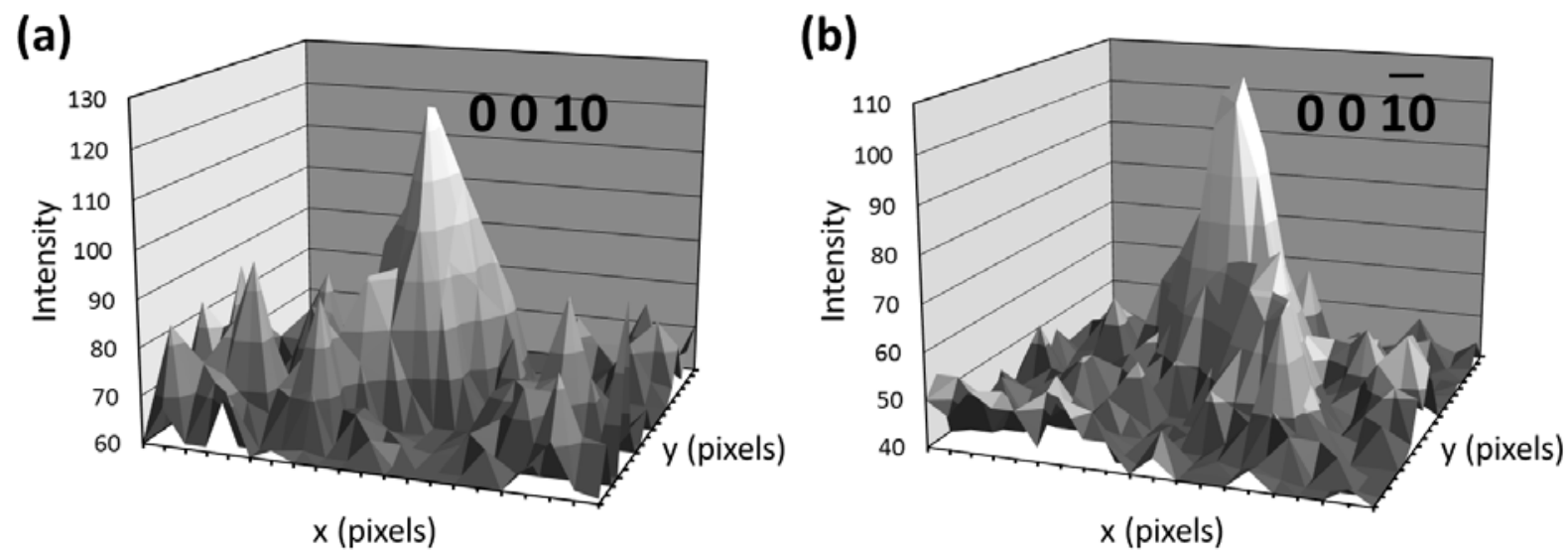

(c)
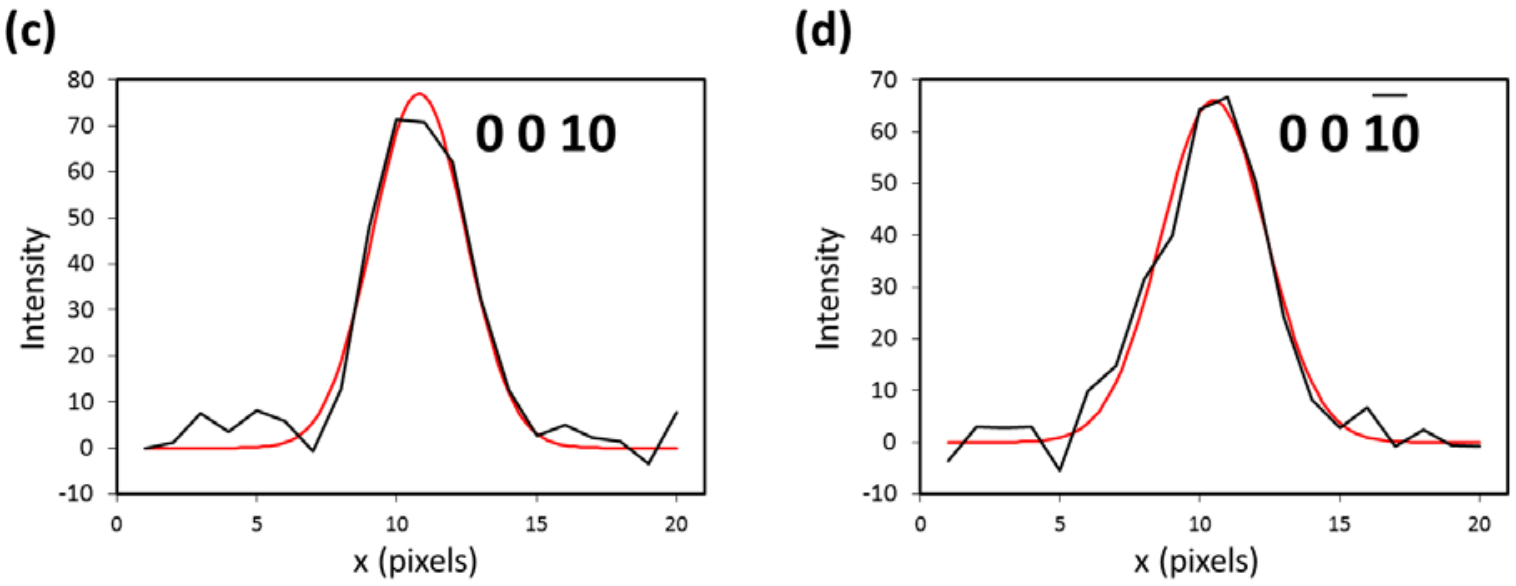

483

484

Figure 2 Intensity profiles recorded by CCD detector. (a) 0010 and (b) $00 \overline{10}$ reflections corresponding to reflection conditions of type $00 l$ with $l=2 n$, which is consistent with the orthorhombic space group Ibca. The rocking curves of the (c) 0010 and (d) $00 \overline{10}$ reflections and their profiles fitted to a Gaussian function. 
(a) Cubic la3d

490

491

492

493

494

495

496

497 (b) Tetragonal $/ 4_{1} /$ acd

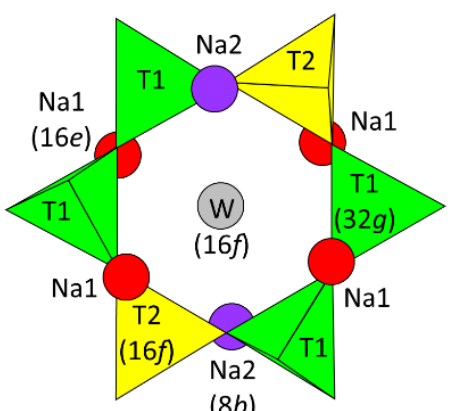

(8b) (c) Orthorhombic lbca

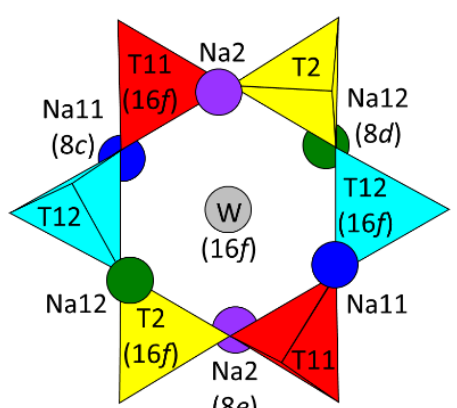

(8e)

Figure 3 The six-membered ring channel and extra-framework species of analcime viewed along the [111] direction. The site splitting from (a) the cubic analcime with space group Ia3d to (c) the orthorhombic analcime with space group Ibca through (b) the tetragonal space group $I 4_{1} /$ acd. The terms in the parentheses denote Wyckoff positions. 
Table 1. Representative chemical compositions of analcimes

\begin{tabular}{|c|c|c|c|c|}
\hline & ideal & $0 \mathrm{~h}$ & $24 \mathrm{~h}$ & $48 \mathrm{~h}$ \\
\hline $\mathrm{SiO}_{2}$ & 54.58 & 57.0 & 57.8 & 57.0 \\
\hline $\mathrm{Al}_{2} \mathrm{O}_{3}$ & 23.16 & 20.4 & 19.3 & 21.0 \\
\hline $\mathrm{Na}_{2} \mathrm{O}$ & 14.08 & 11.7 & 11.7 & 11.8 \\
\hline \multicolumn{5}{|c|}{ Water contents from thermogravimetry } \\
\hline $\mathrm{H}_{2} \mathrm{O}^{*}$ & 8.18 & 8.4 & 8.4 & 8.4 \\
\hline Total (wt \%) & 100.00 & 97.5 & 97.2 & 98.2 \\
\hline \multicolumn{5}{|c|}{ Number of cations on the based of 6 oxygen atoms } \\
\hline $\mathrm{Si}$ & 2.000 & 2.12 & 2.15 & 2.10 \\
\hline $\mathrm{Al}$ & 1.000 & 0.89 & 0.85 & 0.91 \\
\hline$\Sigma T$ & 3.000 & 3.01 & 3.00 & 3.02 \\
\hline $\mathrm{Na}$ & 1.000 & 0.84 & 0.85 & 0.84 \\
\hline $\mathrm{H}_{2} \mathrm{O}$ & 1.000 & 1.04 & 1.04 & 1.03 \\
\hline
\end{tabular}

Notes:

* The $\mathrm{H}_{2} \mathrm{O}$ contents were determined using TG analyses by calculating the weight lost between 100 and $450{ }^{\circ} \mathrm{C}$. 
Table 2. Selected X-ray diffraction data and crystallographic information for analcimes

\begin{tabular}{|c|c|c|c|c|}
\hline \multicolumn{2}{|l|}{ Heating time (h) } & 0 & 24 & 48 \\
\hline \multicolumn{2}{|l|}{ Crystal system } & Cubic & Orthorhombic & Orthorhombic \\
\hline \multicolumn{2}{|l|}{ Space group } & $\operatorname{Ia} 3 d$ & $I b c a$ & $I b c a$ \\
\hline \multirow[t]{3}{*}{ Lattice parameters } & $a(\AA)$ & $13.713(3)$ & $13.727(2)$ & $13.705(2)$ \\
\hline & $b(\AA)$ & & $13.707(2)$ & $13.717(2)$ \\
\hline & $c(\AA)$ & & $13.707(2)$ & $13.706(2)$ \\
\hline Unit cell volume & $V\left(\AA^{3}\right)$ & $2578.6(10)$ & $2579.0(9)$ & $2576.5(9)$ \\
\hline \multicolumn{2}{|l|}{ Z } & 16 & 16 & 16 \\
\hline \multicolumn{2}{|l|}{$D_{\text {calc }}\left(\mathrm{g} / \mathrm{cm}^{3}\right)$} & 2.226 & 2.222 & 2.224 \\
\hline \multicolumn{2}{|l|}{$\mu\left(\mathrm{mm}^{-1}\right)$} & 0.74 & 0.73 & 0.73 \\
\hline \multicolumn{2}{|l|}{$2 \theta_{\max }$} & 54.67 & 56.93 & 57.12 \\
\hline \multirow{3}{*}{\multicolumn{2}{|c|}{ Reciprocal space range $h k l$}} & $-19 \leq h \leq 17$ & $-17 \leq h \leq 18$ & $-17 \leq h \leq 18$ \\
\hline & & $-17 \leq k \leq 17$ & $-16 \leq k \leq 18$ & $-13 \leq k \leq 18$ \\
\hline & & $-17 \leq l \leq 17$ & $-18 \leq l \leq 9$ & $-16 \leq l \leq 17$ \\
\hline \multicolumn{2}{|c|}{ No. of collected reflections } & 7365 & 7264 & 7498 \\
\hline \multicolumn{2}{|c|}{ Unique reflections, $R_{\text {int }}(\%)$} & $247,3.34$ & $1540,2.14$ & $1545,1.31$ \\
\hline \multicolumn{2}{|c|}{ Unique reflections with $F_{\mathrm{o}}>4 \sigma\left(F_{\mathrm{o}}\right)$} & 237 & 1284 & 1383 \\
\hline \multicolumn{2}{|l|}{ No. of parameters } & 23 & 115 & 115 \\
\hline \multicolumn{2}{|l|}{$R_{1}(\%)$} & 1.89 & 2.39 & 2.31 \\
\hline \multicolumn{2}{|l|}{$w R_{2}(\%)$} & 5.34 & 7.33 & 7.58 \\
\hline \multicolumn{2}{|l|}{ GooF } & 1.158 & 1.163 & 1.232 \\
\hline \multicolumn{2}{|c|}{ Largest diffraction peak and hole $\left(\mathrm{e}^{-} / \AA^{3}\right)$} & $0.26 /-0.17$ & $0.30 /-0.32$ & $0.32 /-0.30$ \\
\hline
\end{tabular}




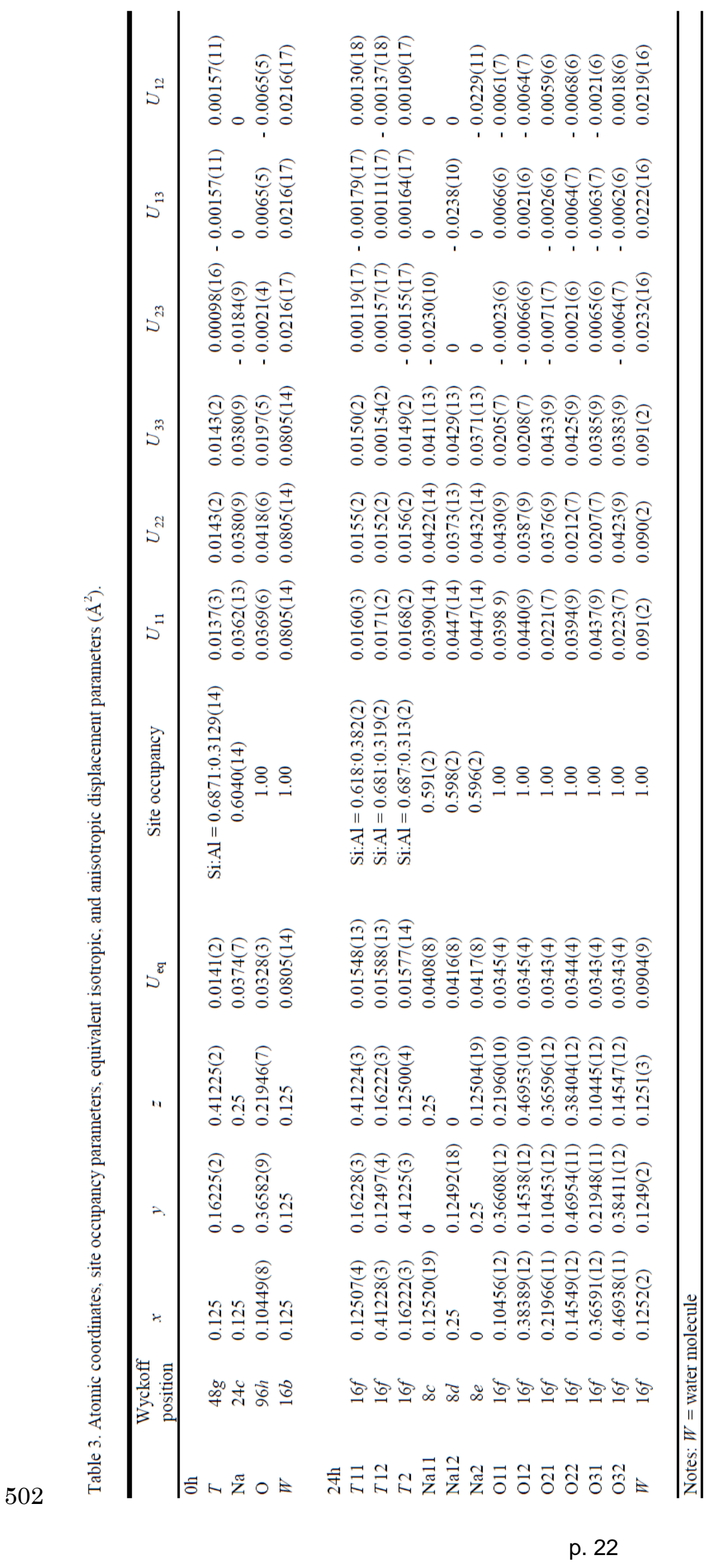




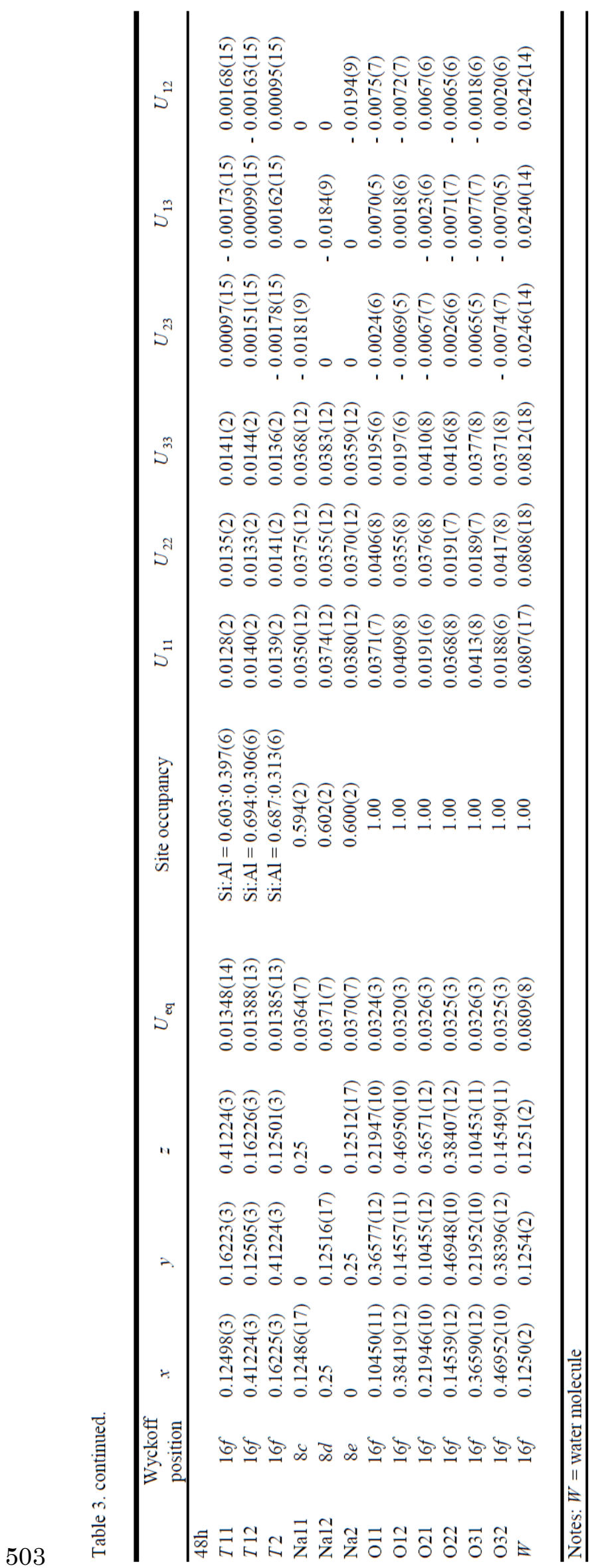


Table 4. Selected bond lengths ( $(A)$ in framework $T$ sites and extra-framework sites.

\begin{tabular}{|c|c|c|c|c|c|}
\hline $\mathrm{Oh}$ & & $24 \mathrm{~h}$ & & $48 \mathrm{~h}$ & \\
\hline$T-O(\times 2)$ & $1.6430(11)$ & $T 11-031$ & $1.6414(15)$ & $T 11-012$ & $1.6416(14)$ \\
\hline$O(\times 2)$ & $1.6465(11)$ & 012 & $1.6416(15)$ & $\mathrm{O} 31$ & $1.6428(15)$ \\
\hline \multirow[t]{13}{*}{ Average } & 1.645 & O32 & $1.6466(16)$ & O32 & $1.6446(15)$ \\
\hline & & $\mathrm{O} 21$ & $1.6477(16)$ & $\mathrm{O} 21$ & $1.6460(15)$ \\
\hline & & Average & 1.644 & Average & 1.644 \\
\hline & & $T 12-011$ & $1.6408(15)$ & $T 12-011$ & $1.6415(14)$ \\
\hline & & O32 & $1.6453(16)$ & $\mathrm{O} 32$ & $1.6420(14)$ \\
\hline & & $\mathrm{O} 22$ & $1.6460(16)$ & $\mathrm{O} 22$ & $1.6456(15)$ \\
\hline & & O31 & $1.6463(16)$ & 031 & $1.6458(15)$ \\
\hline & & Average & 1.645 & Average & 1.644 \\
\hline & & $T 2-\mathrm{O} 22$ & $1.6411(15)$ & $T 2-\mathrm{O} 21$ & $1.6424(15)$ \\
\hline & & $\mathrm{O} 21$ & $1.6425(16)$ & $\mathrm{O} 22$ & $1.6435(15)$ \\
\hline & & 012 & $1.6443(16)$ & 011 & $1.6458(15)$ \\
\hline & & 011 & $1.6457(16)$ & 012 & $1.6467(15)$ \\
\hline & & Average & 1.643 & Average & 1.645 \\
\hline \multirow{9}{*}{$\begin{array}{c}\mathrm{Na}-W(\times 2) \\
\mathrm{O}(\times 4)\end{array}$} & $2.4241(5)$ & Nall- $W(\times 2)$ & $2.421(3)$ & Nall- $W(\times 2)$ & $2.427(2)$ \\
\hline & $2.5007(12)$ & $\mathrm{O} 21(\times 2)$ & $2.502(2)$ & $\mathrm{O} 21(\times 2)$ & $2.501(2)$ \\
\hline & & $\mathrm{O} 32(\times 2)$ & $2.502(2)$ & $\mathrm{O} 32(\times 2)$ & $2.502(2)$ \\
\hline & & Nal2- $W(\times 2)$ & $2.423(3)$ & Nal2- W (×2) & $2.424(2)$ \\
\hline & & $\mathrm{O} 22(\times 2)$ & $2.502(2)$ & $\mathrm{O} 31(\times 2)$ & $2.500(2)$ \\
\hline & & $\mathrm{O} 31(\times 2)$ & $2.502(2)$ & $\mathrm{O} 22(\times 2)$ & $2.5030(19)$ \\
\hline & & $\mathrm{Na} 2-W(\times 2)$ & $2.428(3)$ & $\mathrm{Na} 2-W(\times 2)$ & $2.420(2)$ \\
\hline & & $011(\times 2)$ & $2.504(2)$ & O11 (×2) & $2.4990(19)$ \\
\hline & & $012(\times 2)$ & $2.505(2)$ & $012(\times 2)$ & $2.5006(19)$ \\
\hline \multirow{15}{*}{$\begin{array}{c}\text { W- } \mathrm{Na}(\times 3) \\
\mathrm{O}(\times 6) \\
\mathrm{O}(\times 6)\end{array}$} & $2.4241(5)$ & W- Nall & $2.421(3)$ & $W-\mathrm{Na} 2$ & $2.420(2)$ \\
\hline & $3.4055(14)$ & $\mathrm{Nal} 2$ & $2.423(3)$ & $\mathrm{Nal} 2$ & $2.424(2)$ \\
\hline & $3.5584(14)$ & $\mathrm{Na} 2$ & $2.428(3)$ & Nall & $2.427(2)$ \\
\hline & & $\mathrm{O} 21$ & $3.404(3)$ & 012 & $3.401(3)$ \\
\hline & & O31 & $3.405(3)$ & $\mathrm{O} 32$ & $3.403(3)$ \\
\hline & & $\mathrm{O} 32$ & $3.405(3)$ & 011 & $3.403(3)$ \\
\hline & & $\mathrm{O} 22$ & $3.405(3)$ & 031 & $3.404(3)$ \\
\hline & & 012 & $3.408(3)$ & $\mathrm{O} 22$ & $3.408(3)$ \\
\hline & & 011 & $3.412(3)$ & $\mathrm{O} 21$ & $3.412(3)$ \\
\hline & & O32 & $3.558(3)$ & 011 & $3.553(3)$ \\
\hline & & $\mathrm{O} 21$ & $3.558(3)$ & $\mathrm{O} 21$ & $3.555(3)$ \\
\hline & & $\mathrm{O} 22$ & $3.559(3)$ & 012 & $3.556(3)$ \\
\hline & & O31 & $3.560(3)$ & 031 & $3.557(3)$ \\
\hline & & 011 & $3.562(3)$ & $\mathrm{O} 22$ & $3.561(3)$ \\
\hline & & 012 & $3.569(3)$ & $\mathrm{O} 32$ & $3.567(3)$ \\
\hline
\end{tabular}

504

505 